\title{
Use of near-infrared reflectance spectroscopy for the rapid determination of the digestible energy and metabolizable energy content of corn fed to growing pigs
}

\author{
Juntao Li, Quanfeng Li, Defa Li, Yiqiang Chen, Xiaoxiao Wang, Wenjun Yang and Liying Zhang*
}

\begin{abstract}
Background: The ability of near-infrared reflectance spectroscopy (NIRS) to determine the digestible energy (DE) and metabolizable energy (ME) content of corn fed to growing pigs was tested. One hundred and seventeen corn samples, comprising different planting regions and varieties were collected from all over China in a three-year period. The samples were randomly split into a calibration set $(n=88)$ and a validation set $(n=29)$. The actual and calculated DE and ME content of the corn samples was determined by digestion-metabolism experiments and the prediction equations of Noblet and Perez (J Anim Sci. 71:3389-98,1993). The samples were then subjected to NIRS scanning and calibrations were performed by the modified partial least square (MPLS) regression method based on 77 different spectral pre-treatments. The NIRS equations based on the actually determined and calculated DE and ME were built separately and then validated using validation samples.

Results: The NIRS equations obtained from actually determined DE, the coefficient of determination for calibration $\left(R_{S Q} Q_{c a l}\right)$, cross-validation $\left(R_{C V}^{2}\right)$, and validation $\left(R_{S Q}\right)$ were $0.89,0.87$ and 0.86 , and these values for determined ME were $0.87,0.86$ and 0.86 . For the NIRS equations built from calculated $D E$, the $\mathrm{RSQ}_{c a l}, \mathrm{R}_{\mathrm{CV}}^{2}$, and $\mathrm{RSQ}_{v}$ values were $0.88,0.85$ and 0.84 , and these values for calculated ME were 0.86, 0.84 and 0.82 . Except for the equation based on calculated $M E\left(\mathrm{RPD}_{v}=2.38,<2.50\right)$, the other three equations built from actually determined energy and calculated DE produced good prediction performance $\left(\mathrm{RPD}_{\vee}\right.$ ranging from 2.53 to $\left.2.69,>2.50\right)$ when applied to validation samples.
\end{abstract}

Conclusion: These results indicate that NIRS can be used as a quantitative method for the rapid determination of the available energy in corn fed to growing pigs, and the NIRS equations based on the actually determined energy produced better predictive performance than those built from calculated energy values.

Keywords: Corn, Digestible energy, Growing pigs, Metabolizable energy, Near-infrared reflectance spectroscopy

\section{Background}

The cost of feed usually represents more than $70 \%$ of the total cost of pork production and feed energy generally represents the single largest component of this expense [1]. Corn plays a key role in providing energy in typical Chinese wine diets. In the production of swine feeds in China, formulas are typically made based on the digestible energy (DE) and metabolizable energy (ME)

\footnotetext{
* Correspondence: zhangliying01@sina.com

State Key Lab of Animal Nutrition, College of Animal Science \& Technology, China Agricultural University, Beijing 100193, China
}

values recommended by NRC [2] which only provides the average $\mathrm{DE}$ and ME value (just about $\mathrm{DE}$ and $\mathrm{ME}$ value) for corn. However, because of the use of different corn varieties, planting regions, storage conditions and processing methods, the nutrient levels vary greatly among different sources of corn. Zhao et al. [3] have analyzed the nutritional values of 30 corn samples collected from China, the results indicated that the nutrients varied largely between different samples, ranging from 8.5 to $11.9 \%$ for crude protein $(\mathrm{CP}), 2.3$ to $5.3 \%$ for ether extract (EE), 0.8 to $1.5 \%$ for ash, 1.1 to $3.7 \%$ for crude 
fiber (CF), 6.0 to $21.8 \%$ for neutral detergent fiber (NDF) and 1.8 to $6.8 \%$ for acid detergent fiber (ADF). These differences will typically cause large variations in the DE and ME content of corn when fed to growing pigs [4], and thus will have economic implications for swine producers. Therefore, in order to achieve accurate feed formulation, and decrease the cost of pork production, it is important to precisely determine the actual $\mathrm{DE}$ and $\mathrm{ME}$ content of corn before its use.

At present, the evaluation of DE and ME of feed ingredients is mainly made through traditional digestionmetabolism experiments, which are time consuming, labor intensive, expensive and can potentially pollute the environment [5]. Therefore, it is essential to establish a rapid and accurate method to measure the energy value of feed ingredients. Based on the analysis of chemical components, several equations have been proposed to estimate the energy values of complete diets $[6,7]$ and feed ingredients, including corn [8], barley [9], corn co-products [10,11], and corn gluten meals [12] fed to pigs, but this approach is limited by its lack of speed and poor repeatability.

As a rapid, non-destructive and relatively inexpensive technology, near-infrared reflectance spectroscopy (NIRS) has been successfully applied in the feed industry to predict the chemical composition of corn [13-15]. Some studies have also investigated the possibility of predicting the DE and ME content in barley $[4,16]$ and wheat $[17,18]$ by NIRS, but the results obtained were not satisfying due to the low number of samples used and relatively small intersample variability. In addition, to the best of our knowledge, there has been no report about the rapid prediction of swine DE and ME content in corn by NIRS. In this study, to improve the performance of this technology, the number of collected corn samples was increased and the inter-sample variability was enlarged by picking corn samples from different planting regions and varieties. Furthermore, a comparison was made between the NIRS equations derived from reference data determined by metabolism experiments and the prediction equations of Noblet and Perez [6].

\section{Methods}

\section{Sample preparation}

Between 2009 and 2011, a total of 117 corn samples from different planting regions and varieties were collected from all over China. Eighty eight corn samples were randomly chosen as a calibration set and the remaining 29 samples were used as a validation set. For the development of NIRS calibrations, corn samples were ground in a Universal High-speed Grinder FW-100 (Ever Bright Medical Instrument Co., company, Beijing, China) through a $0.42 \mathrm{~mm}$ screen. Samples were stored at $-18{ }^{\circ} \mathrm{C}$ and brought to room temperature $\left(24{ }^{\circ} \mathrm{C}\right)$ prior to chemical analysis and NIRS scanning.

\section{Reference data analysis}

Samples were analyzed using the methods of AOAC International [19]. Analysis were conducted for moisture (AOAC method 930.15), crude protein (CP; AOAC method 999.03), ash (AOAC method 975.03) and ether extract (EE, AOAC method 2003.06). Neutral detergent fiber (NDF) and acid detergent fiber (ADF) were determined using filter bags and fiber analyzer equipment (Fiber Analyzer, Ankom Technology, Macedon, NY) following a modification of the procedure of van Soest et al. [20]. The concentration of NDF was analyzed using heat stable $\alpha$ - amylase and sodium sulphite without correction for insoluble ash. The ADF fraction was analyzed in a separate sample. The DE and ME contents of corn samples were determined by both digestion-metabolism experiments and the prediction equations of Noblet and Perez [6].

The Animal Welfare Committee of China Agricultural University (Beijing, China) approved the animal care protocol used for the digestion-metabolism experiments. One hundred and seventeen diets were formulated to include one specific corn sample (96.8\%), dicalcium phosphate (1.7\%), limestone (0.6\%), salt (0.3\%), mineral and vitamin premix $(0.5 \%)$ and antioxidant $(0.1 \%)$. Corn was considered to be the only source of energy in the diet, assuming that the contribution of energy from vitamin and mineral premixes was negligible. Vitamins and minerals were supplied at levels exceeding the requirements of 20 to $50 \mathrm{~kg}$ growing pigs recommended by NRC [21].

The whole experiment consisted of six digestibility trials and was conducted from October 2011 to May 2012 under similar experimental conditions. There are 10 metabolism rooms, and each room has 12 metabolism cages. Twenty diets were measured for each of the first five trials, and 17 diets were measured for the sixth trial. A total of 702 growing crossbred barrows [(Yorkshire $\times$ Landrace $) \times$ Duroc] with similar genetic background and initial weight of $35 \pm 1.2 \mathrm{~kg}$ were used according to a completely randomized design, and each diet was tested on six pigs.

Pigs were housed individually in stainless steel metabolism cages $(1.4 \mathrm{~m} \times 0.45 \mathrm{~m} \times 0.6 \mathrm{~m})$ in an environmentally controlled room $\left(22 \pm 2{ }^{\circ} \mathrm{C}\right)$. The daily feed allowance was equivalent to $4 \%$ of body weight at the beginning of each period [22]. It was divided into two equal parts and fed at 0800 and $1700 \mathrm{~h}$ in mash form. Water was available ad libitum through a drinking nipple. Pigs were fed experimental diets for $14 \mathrm{~d}$, including $7 \mathrm{~d}$ for adaptation and $5 \mathrm{~d}$ for fecal and urine collection. The fecal marker $(10 \mathrm{~g} / \mathrm{kg})$ were included in the morning meal on $\mathrm{d} 8$ (chromic oxide) and in the morning meal on $\mathrm{d} 13$ (ferric oxide), and fecal collections were initiated when chromic oxide appeared in the feces and ceased when ferric oxide appeared [22]. Urine collections were started on d 8 at $1700 \mathrm{~h}$ and ceased on $\mathrm{d} 11$ at $1700 \mathrm{~h}$. The collection and 
sample preparation for feces and urine were conducted according to the methods described by Song et al. [23] The gross energy (GE) in corn samples, diets, feces, and urine samples was analyzed via Adiabatic Oxygen Bomb Calorimeter (Parr Instruments, Moline, IL). Two pieces of well-folded filter paper with known quality were placed in the crucible which was provided by the Adiabatic Oxygen Bomb Calorimeter (Parr Instruments, Moline, IL), and then $4 \mathrm{~mL}$ of each urine sample was added to the filter paper. After that, the filter paper with crucible were put into a vacuum dryer for drying at $60{ }^{\circ} \mathrm{C}$. The dried filter paper with crucible were placed in the Adiabatic Oxygen Bomb Calorimeter (Parr Instruments, Moline, IL) for the analysis of total gross energy. At last, the combustion heat of the filter paper was determined and deducted from the total gross energy. According to the method above, the gross energy of urine samples were analyzed. The $\mathrm{DE}$ and ME contents of corn were calculated by the direct method [22].

$\mathrm{DE}$ and ME (dry matter basis) of corn samples fed to growing pigs were also calculated using the following equations of Noblet and Perez [6]:

$$
\begin{aligned}
\mathrm{DE}(\mathrm{MJ} / \mathrm{kg})= & (4,168-9.1 \times \mathrm{Ash}+1.9 \times \mathrm{CP} \\
& +3.9 \times \mathrm{EE}-3.6 \times \mathrm{NDF}) \\
& \times 4.18 / 1,000 \\
\mathrm{ME}(\mathrm{MJ} / \mathrm{kg})= & \mathrm{DE} \times(1.003-0.00021 \times \mathrm{CP})
\end{aligned}
$$

The standard error of laboratory (SEL) was calculated according to the method of Kovalenko et al. [24]. The relative standard error of laboratory (RSEL) was calculated as SEL/mean $\times 100 \%$.

\section{NIRS spectra collection}

Spectral data collection, processing and calibration were conducted with the chemometrics software WinISI II Ver. 1.50 (Infrasoft International, Port Matida, PA). Spectral measurements were performed using a FOSS NIRSystem 6500 Spectrophotometer (FOSS NIRSystems Inc., Silver Springs, MD). Samples were placed in a $1 / 4$ rectangular cup $(5.7 \mathrm{~cm} \times 4.6 \mathrm{~cm})$ and then scanned in the diffusedreflectance mode. Each spectrum represented the average of 32 scans and was recorded as the logarithm of the reciprocal of reflectance $(\log (1 / \mathrm{R}))$. Each sample was measured in two independent subsamples and the average spectrum was used for chemometric analysis [25]. Data were stored at every $2 \mathrm{~nm}$ interval in the wavelength range from 400 to 2,498 $\mathrm{nm}$ [25].

\section{Calibration and validation process}

All calibration equations were developed using the modified partial least square (MPLS) regression method using the calibration set $(n=88)$ [26]. Seventy seven different spectral pre-treatments including 7 scatter correction methods combined with 11 mathematical treatments $(0,0,1,1 ; 1,4,4,1 ; 2,4,4,1 ; 1,8,8,1 ; 2,8,8,1 ; 1,10,10,1$; $2,10,10,1 ; 1,12,12,1 ; 2,12,12,1 ; 1,16,16,1 ; 2,16,16,1)$ were used. They include a mathematical treatment that uses the raw spectra, or their first or second derivatives (to remove background differences whiles enhancing spectral differences); combined with gap sizes in data points over which the derivative is calculated; and a smoothing algorithm that reduces random noise in the spectral data. For example in $2,4,4,1$, the first number indicates the order of derivative function (two is the second derivative of $\log (1 / R))$; the second number is the gap (length in $\mathrm{nm}$ ); the third number represents the number of data points (segment length) used in the first smoothing and the fourth number is the number of data points in the second smoothing which is normally set at 1 for no second smoothing. The scatter correction methods included Original Data (None), Standard Normal Variate plus Detrend correction (SNVD), Standard Normal Variate (SNV), Detrend correction (Detrend), Standard Multiplicative Scatter Correction (SMSC), Weighted Multiplicative Scatter Correction (WMSC) and Inverse Multiplicative Scatter Correction (IMSC).

Cross-validation was used to select the optimal number of partial least square factors and to avoid overfitting [27]. The calibration set was divided into 6 cross-validation groups. The optimal number of factors was considered as that which produced the minimum standard error of cross-validation (SECV). The calibration was developed using a maximum of two passes for outlier elimination. Outliers were defined as $H$ outliers (global $H \geq 10$, spectral outliers) [28] and $T$ outliers ( $T>2.5$, samples which did not fit the calibration model).

Calibration models were assessed by statistical parameters including the coefficient of determination for calibration $\left(\mathrm{RSQ}_{\mathrm{cal}}\right)$, the standard error of calibration (SEC), the coefficient of determination for cross-validation $\left(\mathrm{R}_{\mathrm{CV}}^{2}\right)$, and the standard error of cross-validation (SECV). Optimum calibrations equations were obtained with the highest $\mathrm{RSQ}_{\mathrm{cal}}$ or $\mathrm{R}_{\mathrm{CV}}^{2}$ and the lowest SEC or SECV values. The ratio of standard deviation (SD) of the original data to the SECV (ratio of prediction to deviation, RPD) [29] was also used to evaluate calibration performance.

Validation was performed using the validation set $(n=29)$. The coefficient of determination for validation $\left(\mathrm{RSQ}_{\mathrm{v}}\right)$ and standard error of prediction (SEP) invalidation were used to test whether the equations obtained had good predictive performance. RPD value was expressed as $R P D_{v}(S D / S E P)$ for validation. NIRS equations with RPD $\left(R P D_{c v}\right.$ and $\left.R P D_{v}\right)$ values greater than 2.50 can be successfully applied to routine analysis [30]. 


\section{Results}

\section{Variability in energy content}

Table 1 shows the chemical composition and the DE and ME content of the corn fed to growing pigs. As for the entire set of samples, the concentration of CP, EE, ash, ADF and NDF in DM ranged from 7.80 to $11.00 \%, 2.09$ to $4.97 \%, 0.83$ to $1.82 \%, 1.73$ to $3.69 \%$ and 6.40 to $19.37 \%$, respectively. The standard error of laboratory (SEL) and relative standard error of laboratory (RSEL) values for these chemical components ranged from 0.015 to $0.228 \%$ and 0.62 to $2.29 \%$, respectively. The actual $\mathrm{DE}$ and $\mathrm{ME}$ values determined by digestionmetabolism experiments $\left(D_{D}\right.$ and $\left.M E_{D}\right)$ varied from 14.99 to $17.50 \mathrm{MJ} / \mathrm{kg} \mathrm{DM}$ and 14.42 to $17.05 \mathrm{MJ} / \mathrm{kg} \mathrm{DM}$, respectively, while these values calculated according to the equations of Noblet and Perez [6] $\left(\mathrm{DE}_{\mathrm{c}}\right.$ and $\left.\mathrm{ME}_{\mathrm{c}}\right)$ varied from 14.74 to $17.72 \mathrm{MJ} / \mathrm{kg} \mathrm{DM}$ and 14.43 to $17.42 \mathrm{MJ} / \mathrm{kg} \mathrm{DM}$, respectively. The entire set, calibration set and validation set for each chemical component and energy fraction had similar sample distributions with similar mean values, standard deviations (SD) and coefficients of variation $(\mathrm{CV})$.

\section{Spectral pre-treatment}

Figure 1 shows the reflectance spectra of corn samples using different spectral pre-treatments. The original NIR spectra of all the corn samples used in this study are shown in Fig. 1 (a). Besides broad peaks and considerable baseline shifts, parallel shifts between the spectra caused by scattering of samples were also observed [31]. In order to resolve these problems, a number of mathematical treatments combined with different scatter correction algorithms were tested on the spectra. As shown in Fig. 1 (b), after being treated with the 2,4,4,1 mathematical method, the spectral differences were significantly enhanced with more defined absorption peaks, and the baseline shifts were also corrected. Figure 1 (c) shows the spectra treated with the 2,4,4,1 mathematical method combined with the SNVD scatter correction method, in which the spectral variation has been greatly reduced.

\section{Calibration and validation}

The calibration and cross-validation statistics are shown in Table 2. Good NIRS prediction equations were obtained for both actually determined and calculated DE and $\mathrm{ME}$, with relatively high $\mathrm{RSQ}_{\text {cal }}(0.86-0.89), \mathrm{R}_{\mathrm{CV}}^{2}$ (0.84-0.87) and $\mathrm{RPD}_{\mathrm{cv}}$ values (2.54-2.85) greater than 2.50. When applying these equations to validation samples, three of the four equations obtained good prediction performance with relatively high $\mathrm{RSQ}_{\mathrm{v}}(0.84-0.86)$ and $R P D_{v}$ values $(2.53-2.69,>2.50)$.

Only the prediction equation for $\mathrm{ME}_{\mathrm{C}}$ produced a relatively poor result with $\mathrm{RSQ}_{\mathrm{v}}$ of 0.82 and $\mathrm{RPD}_{\mathrm{v}}$ of $2.38(<2.50)$ (Table 3). The relationship between analyzed values and NIRS predicted values for both actually determined and calculated DE and ME for the validation set are shown in Fig. 2. Except for $\mathrm{ME}_{\mathrm{C}}\left(R^{2}=0.82\right)$, the regression plots for $\mathrm{DE}_{\mathrm{D}}, \mathrm{ME}_{\mathrm{D}}$ and $\mathrm{DE}_{\mathrm{C}}$ showed good performance with $R^{2}$ all greater than 0.84 . The results of linear regression analysis between actually $D_{D}$ values and values predicted by NIRS equations built from $D_{C}$ was not satisfactory with a relatively low $R^{2}(0.77)$, and the same situation was found for $\operatorname{ME}\left(R^{2}=0.78\right)$.

Table 1 Chemical composition and digestible energy (DE) and metabolizable energy (ME) content of corn fed to growing pigs determined directly or by prediction equations (MJ/kg, dry matter basis)

\begin{tabular}{|c|c|c|c|c|c|c|c|c|c|c|c|c|c|c|c|c|c|}
\hline \multirow[b]{2}{*}{ Items $^{\mathrm{e}}$} & \multicolumn{5}{|c|}{ Entire set $(n=117)$} & \multirow[b]{2}{*}{$\mathrm{SEL}^{\mathrm{C}}$} & \multirow[b]{2}{*}{ RSEL $^{d}$} & \multicolumn{5}{|c|}{ Calibration set $(n=88)$} & \multicolumn{5}{|c|}{ Validation set $(n=29)$} \\
\hline & Min & Max & Mean & $\mathrm{SD}^{\mathrm{a}}$ & $C V^{b}$ & & & Min & Max & Mean & $\mathrm{SD}^{\mathrm{a}}$ & $C V^{b}$ & $\overline{\operatorname{Min}}$ & Max & Mean & $\mathrm{SD}^{\mathrm{a}}$ & $C V^{b}$ \\
\hline Moisture, \% & 10.90 & 14.00 & 12.63 & 0.892 & 7.06 & 0.129 & 1.02 & 10.90 & 14.00 & 12.61 & 0.930 & 7.37 & 10.94 & 13.96 & 12.69 & 0.881 & 6.94 \\
\hline$C P, \%$ & 7.80 & 11.00 & 9.41 & 0.718 & 7.63 & 0.057 & 0.62 & 7.80 & 11.00 & 9.42 & 0.709 & 7.53 & 7.85 & 10.95 & 9.39 & 0.732 & 7.80 \\
\hline $\mathrm{EE}, \%$ & 2.09 & 4.97 & 3.87 & 0.580 & 14.99 & 0.025 & 0.64 & 2.09 & 4.97 & 3.88 & 0.592 & 15.25 & 2.13 & 4.91 & 3.85 & 0.572 & 14.86 \\
\hline Ash, \% & 0.83 & 1.82 & 1.41 & 0.257 & 18.21 & 0.015 & 1.06 & 0.83 & 1.82 & 1.40 & 0.258 & 18.45 & 0.85 & 1.78 & 1.43 & 0.253 & 17.67 \\
\hline ADF, \% & 1.73 & 3.69 & 2.33 & 0.443 & 19.02 & 0.053 & 2.29 & 1.73 & 3.69 & 2.31 & 0.459 & 19.89 & 1.81 & 3.59 & 2.38 & 0.444 & 18.64 \\
\hline NDF, \% & 6.40 & 19.37 & 12.02 & 3.083 & 25.65 & 0.228 & 1.91 & 6.40 & 19.37 & 11.98 & 3.165 & 26.42 & 7.23 & 19.19 & 12.11 & 3.039 & 25.10 \\
\hline$D E_{D}^{f}$ & 14.99 & 17.50 & 16.37 & 0.751 & 4.59 & - & - & 14.99 & 17.50 & 16.39 & 0.757 & 4.62 & 15.02 & 17.48 & 16.31 & 0.741 & 4.54 \\
\hline$M E_{D}^{f}$ & 14.42 & 17.05 & 15.96 & 0.734 & 4.60 & - & - & 14.42 & 17.05 & 15.97 & 0.740 & 4.64 & 14.49 & 17.02 & 15.93 & 0.730 & 4.58 \\
\hline$D E_{C}{ }^{g}$ & 14.74 & 17.72 & 16.42 & 0.718 & 4.37 & - & - & 14.74 & 17.72 & 16.43 & 0.725 & 4.41 & 14.81 & 17.69 & 16.38 & 0.708 & 4.32 \\
\hline$M E_{C}^{g}$ & 14.43 & 17.42 & 16.16 & 0.697 & 4.31 & - & - & 14.43 & 17.42 & 16.18 & 0.709 & 4.38 & 14.61 & 17.35 & 16.10 & 0.676 & 4.20 \\
\hline
\end{tabular}

${ }^{\mathrm{a}}$ Standard deviation

${ }^{\mathrm{b}}$ Coefficient of variation

'Standard error of laboratory

${ }^{\mathrm{d}}$ Relative standard error of laboratory

${ }^{e} C P$ crude protein, $E E$ ether extract, $A D F$ acid detergent fiber, NDF neutral detergent fiber

${ }^{f} D E_{D}$ and $M E_{D}$ values determined by digestion-metabolism experiments using growing pigs

${ }^{9} \mathrm{DE}_{\mathrm{C}}$ and $\mathrm{ME}_{\mathrm{C}}$ values calculated according to the equations of Noblet and Perez [6] 


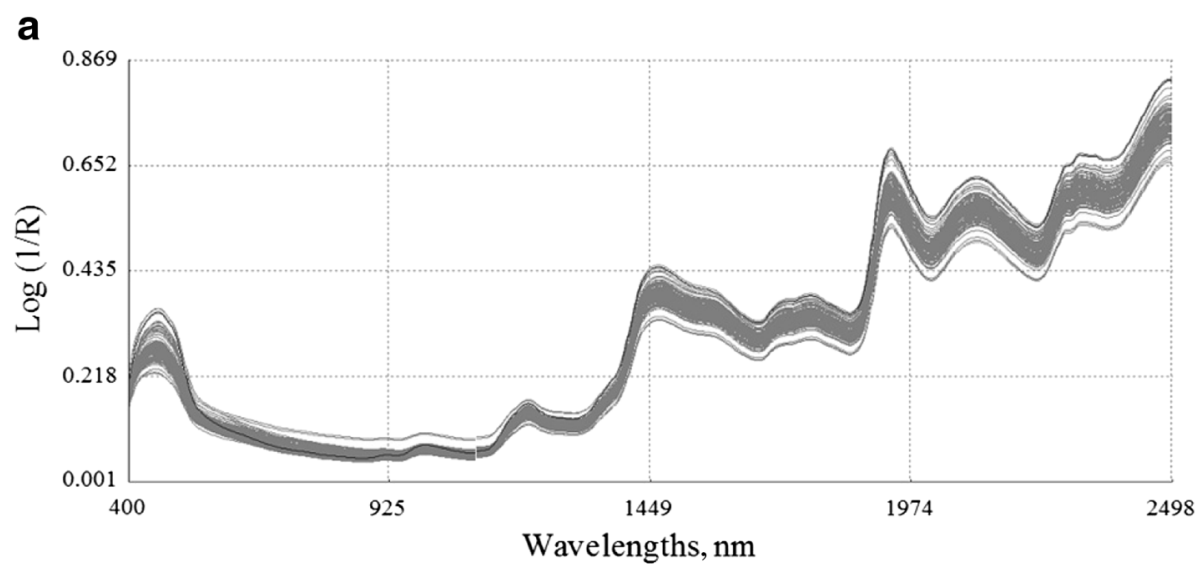

b

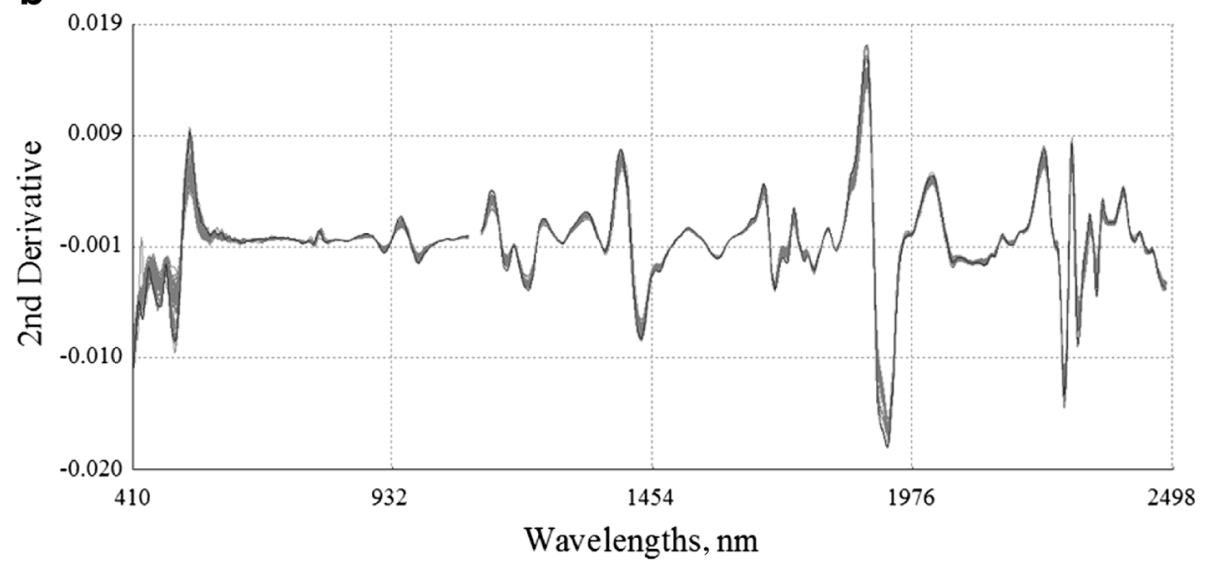

C

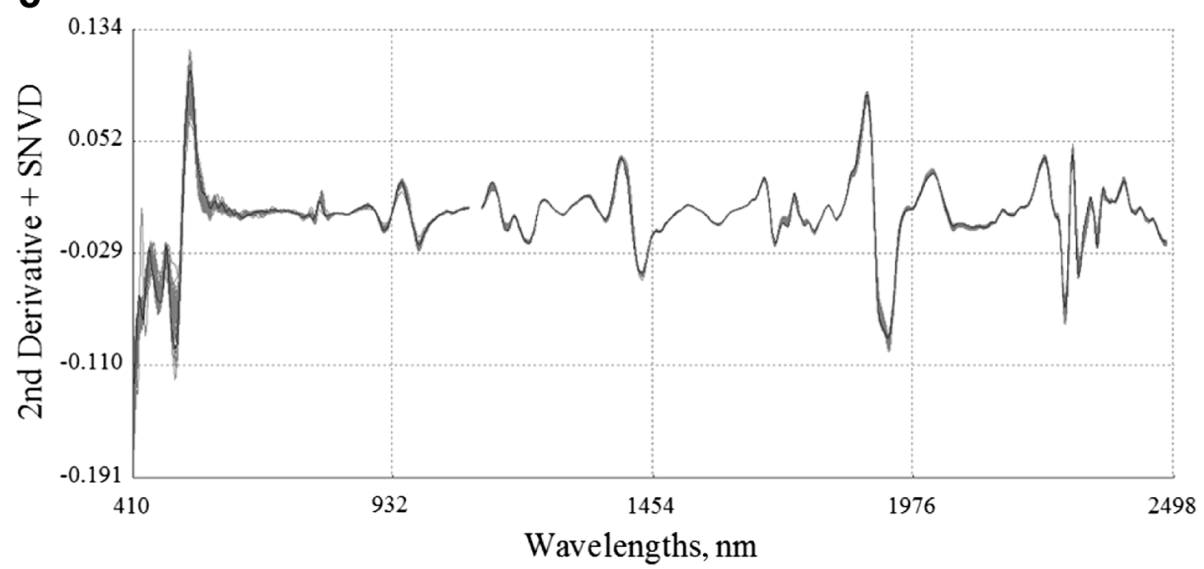

Fig. 1 Reflectance spectra of corn $(n=117)$ in different spectral pre-treatments. (a) Raw spectra; (b): Derivative 2,4,4,1; (c): Derivative 2,4,4,1+ Standard normal variate plus detrend correction (SNVD)

\section{Discussion}

The average CP, EE, ash, ADF and NDF values of corn samples measured in this study were similar to that presented by NRC [2], but the variation in these components were larger than previous studies $[3,15,32]$. In this study, relatively precise $\mathrm{DE}_{C}$ and $\mathrm{ME}_{C}$ values were obtained due to the accurate results of the chemical analysis with low SEL and RSEL values (Table 1). It has practical application values to accurately predict the DE and ME content which could reduce the need for metabolism studies.

The average actual $\mathrm{DE}_{\mathrm{D}}$ and $M \mathrm{E}_{\mathrm{D}}$ values of the corn samples determined by digestion-metabolism experiments were similar with the values published by the 
Table 2 Calibration and cross-validation statistics of digestible energy (DE) and metabolizable energy (ME) of corn fed to growing pigs (MJ/kg, dry matter basis)

\begin{tabular}{|c|c|c|c|c|c|c|c|c|c|c|c|}
\hline \multirow[b]{2}{*}{ Items } & \multirow[b]{2}{*}{ Derivative } & \multirow[b]{2}{*}{ Scatter } & \multirow[b]{2}{*}{ Factors } & \multicolumn{5}{|c|}{ Calibration } & \multicolumn{3}{|c|}{ Cross-validation } \\
\hline & & & & $\bar{n}$ & Mean & $\mathrm{SD}^{\mathrm{a}}$ & $\mathrm{SEC}^{\mathrm{b}}$ & $\overline{\mathrm{RSQ}_{\mathrm{cal}}{ }^{\mathrm{c}}}$ & $\mathrm{SECV}^{\mathrm{d}}$ & $\mathrm{R}^{2} \mathrm{CV}^{\mathrm{e}}$ & $\overline{R P D_{c v}{ }^{\dagger}}$ \\
\hline$\overline{D E_{D}{ }^{g}}$ & $2,12,12,1$ & SNVD & 13 & 86 & 16.41 & 0.759 & 0.196 & 0.89 & 0.266 & 0.87 & 2.85 \\
\hline$M E_{D}{ }^{g}$ & $2,10,10,1$ & SNVD & 11 & 85 & 15.98 & 0.741 & 0.206 & 0.87 & 0.267 & 0.86 & 2.78 \\
\hline$D E_{C}{ }^{h}$ & $2,10,10,1$ & SNVD & 12 & 87 & 16.46 & 0.728 & 0.201 & 0.88 & 0.273 & 0.85 & 2.67 \\
\hline$M E_{C}{ }^{h}$ & $2,8,8,1$ & SNVD & 10 & 86 & 16.20 & 0.711 & 0.215 & 0.86 & 0.280 & 0.84 & 2.54 \\
\hline
\end{tabular}

${ }^{\mathrm{a}}$ Standard deviation

${ }^{\mathrm{b}}$ Standard error of calibration

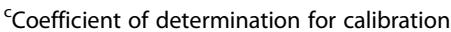

${ }^{\mathrm{d}}$ Standard error of cross-validation

${ }^{e}$ Coefficient of determination for cross-validation

${ }^{\mathrm{R}} \mathrm{RPD}_{\mathrm{CV}}=\mathrm{SD} / \mathrm{SECV}$

${ }^{9} D E_{D}$ and $M E_{D}$ values determined by digestion-metabolism experiments using growing pigs

${ }^{\mathrm{h}} \mathrm{DE} \mathrm{C}_{\mathrm{C}}$ and $\mathrm{ME}_{\mathrm{C}}$ values calculated according to the equations of Noblet and Perez [6]

NRC [2], while the $D_{C}$ and $M E_{C}$ values were a little higher than the NRC [2] values. Due to the large variation in chemical composition of the collected corn samples, relatively wide ranges in corn $\mathrm{DE}$ and $\mathrm{ME}$ contents were obtained with relatively high coefficients of variation ( $\mathrm{CV}$ all beyond $4.20 \%$, Table 1 ), which is essential for the development of robust prediction equations by NIRS $[4,5,18]$. With similar sample distributions, the calibration set and validation set samples were also suitable for the establishment of excellent NIR prediction equations [26].

Due to the relatively large number and precise reference data with large variation in $\mathrm{DE}$ and $\mathrm{ME}$ content of the corn samples used here, good calibration equations were obtained for both actually determined and calculated $\mathrm{DE}$ and $\mathrm{ME}$, and except for the prediction equation built from $\mathrm{ME}_{\mathrm{C}}$, good predictive performances were obtained for all the other three prediction equations which can be used for routine analysis. In previous studies, limited sample numbers and analysis error made it difficult to gain excellent NIRS performance for DE and ME content for pigs. Garnsworthy et al. [18] predicted the DE by NIRS using 33 wheat samples, but their

Table 3 Validation statistic of DE and ME of corn fed to growing pigs (MJ/kg, dry matter basis)

\begin{tabular}{lllllll}
\hline Constituent & $n$ & Mean & $\mathrm{SD}^{\mathrm{a}}$ & $\mathrm{SEP}^{\mathrm{b}}$ & $\mathrm{RSQ}_{v}{ }^{\mathrm{c}}$ & $\mathrm{RPD}_{v}{ }^{\mathrm{d}}$ \\
\hline $\mathrm{DE}_{\mathrm{D}}{ }^{\mathrm{e}}$ & 29 & 16.31 & 0.741 & 0.275 & 0.86 & 2.69 \\
$\mathrm{ME}_{\mathrm{D}}{ }^{\mathrm{e}}$ & 29 & 15.93 & 0.730 & 0.276 & 0.86 & 2.64 \\
$\mathrm{DE}_{\mathrm{C}}{ }^{\mathrm{f}}$ & 29 & 16.38 & 0.708 & 0.279 & 0.84 & 2.53 \\
$\mathrm{ME}_{\mathrm{C}}{ }^{\mathrm{f}}$ & 29 & 16.10 & 0.676 & 0.284 & 0.82 & 2.38 \\
\hline
\end{tabular}

${ }^{\text {aStandard deviation }}$

${ }^{\mathrm{b}}$ Standard error of prediction

'Coefficient of determination for validation

${ }^{\mathrm{d}} \mathrm{RPD}_{\mathrm{v}}=\mathrm{SD} / \mathrm{SEP}$

${ }^{\mathrm{e}} \mathrm{DE}$ and ME values determined by digestion-metabolism experiments using growing pigs

${ }^{\mathrm{f}} \mathrm{DE}$ and $\mathrm{ME}$ values calculated according to the equations of Noblet and Perez [6] results were not satisfying with a low coefficient of determination $\left(R^{2}=0.17\right)$. For a set of duplicate scans from 39 barley samples, a relatively poor result was also reported with a $R_{C V}^{2}$ of 0.69 for swine DE content [16]. Because of the inter-laboratory variation on the reference sample set, the performance of NIRS calibrations were also not good in the studies of [17] $\left(R_{\text {cal }}^{2}=0.72\right.$, $\left.\mathrm{RPD}_{\mathrm{CV}}=2.13\right)$ and [4] $\left(\mathrm{R}_{\mathrm{CV}}^{2}=0.79\right)$. Although good calibration results for $\mathrm{DE}$ and $\mathrm{ME}\left(\mathrm{RSQ}_{\mathrm{cal}}=0.87\right.$ and 0.86 , respectively) were obtained in the study of Aufrère et al. [33], there was no data presented on validation statistics. It is probable that the relationship between actual and NIRS predicted values would be weakened in some validation exercises. Xiccato et al. [34] predicted the DE concentration of rabbit diets by NIRS and reported a high coefficient of determination $\left(R^{2}=0.90\right)$. However with validation, this relationship was weakened and the SECV increased. This result has also been reported by Deaville et al. [35] who predicted in vivo ME of whole crop cereals fed to sheep by NIRS and found that the $R^{2}$ declined considerably between calibration $\left(R^{2}=0.87\right)$ and cross-validation process $\left(R_{C V}^{2}=0.79, R^{2} D_{c v}=2.16\right)$. As a result, in order to decide whether the NIRS prediction performance is good or not, both results of calibration and validation should be taken into consideration.

In the present study, using the 2nd instead of 1 st derivative gave better prediction performance, which is in agreement with previous studies $[4,5,24,36]$. With the treatment by the 2 nd derivative, the spectral differences were enhanced [37] and baseline shifts caused by sample particle size was removed [38]. Among different scatter correction methods used, the Standard Normal Variate plus Detrend correction (SNVD) gave the best results for both actually determined and predicted $\mathrm{DE}$ and ME.

Compared with the NIRS prediction equations built from $\mathrm{DE}_{\mathrm{C}}$ or $\mathrm{ME}_{\mathrm{C}}$ values, the prediction equation obtained from actually $\mathrm{DE}_{\mathrm{D}}$ or $\mathrm{ME}_{\mathrm{D}}$ values received a better predictive 

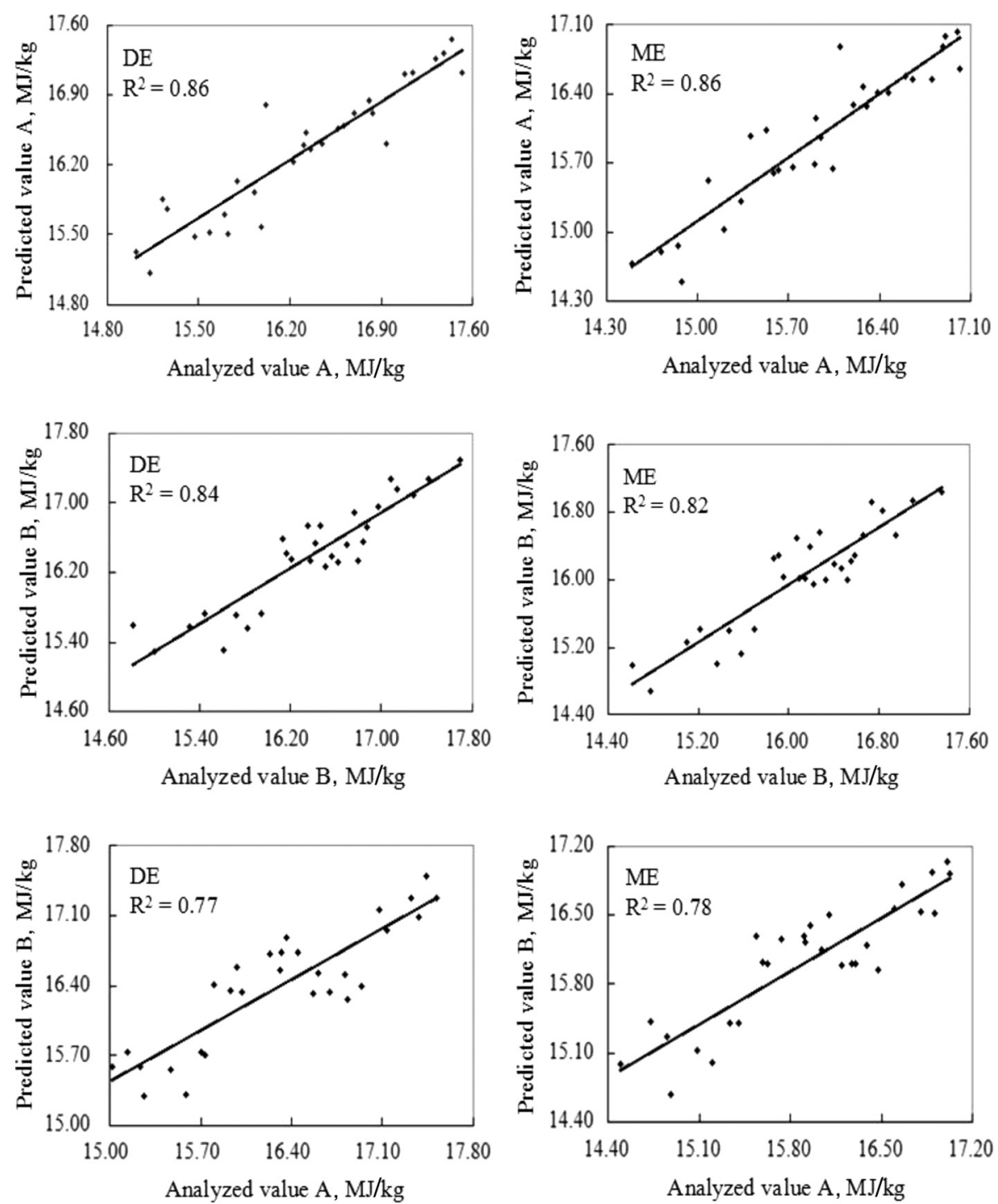

Fig. 2 Plot of analyzed values versus NIRS predicted values of energy content of corn. Analyzed value A and analyzed value B were determined by digestion-metabolism experiments and the prediction equations of Noblet and Perez [6], respectively; Predicted value A and predicted value B were predicted by NIRS calibration equation built with energy values determined by digestion-metabolism experiments and the prediction equations of Noblet and Perez [6], respectively

performance with higher $\mathrm{RSQ}_{\mathrm{v}}$ and $\mathrm{RPD}_{\mathrm{v}}$ values and lower $\mathrm{SEP}$ value. In addition, the relationship between $\mathrm{DE}_{\mathrm{D}}$ or $M E_{D}$ and values predicted by NIRS equations built from $\mathrm{DE}_{\mathrm{C}}$ or $\mathrm{ME}_{\mathrm{C}}$ was relatively poor. These results indicate that it is better to do the NIRS calibration for DE and ME based on reference data determined by digestion-metabolism experiments. The reason for this result might be that the prediction equations built by Noblet and Perez [6] were for complete feeds for pigs, when they were extrapolated to predict the $\mathrm{DE}$ and $\mathrm{ME}$ content of feed ingredients, the performance of them might be decreased because of the differences in chemical composition between complete feed and individual ingredients [39]. However, when time is limited and the conditions do not allow for digestion- metabolism experiments, the $\mathrm{DE}_{C}$ and $\mathrm{ME}_{\mathrm{C}}$ values could also be used to do the NIRS calibrations with an acceptable performance [5]. In practice, the good NIRS prediction performance for DE and ME obtained in this study offered an advantage to effective use of corn resources in swine production.

\section{Conclusion}

In summary, the results obtained in this study indicate that NIRS can be used as a routine analysis method for the rapid determination of DE and ME content in corn fed to growing pigs. Optimization of spectral pre-treatment methods can improve the NIRS calibration and prediction performance. NIRS prediction equations built from actual 
$\mathrm{DE}$ and ME content determined by digestion-metabolism experiments showed better prediction performance than those based on predicted DE and ME content calculated according to the equations of Noblet and Perez [6], but the latter could also be used for the NIRS calibration with an acceptable performance in some situations.

\section{Abbreviations}

$A D F$, acid detergent fiber; $C F$, crude fiber; $C P$, crude protein; $C V$, coefficient of variation; DDGS, distillers dried grains with solubles; $\mathrm{DE}$, digestible energy; DM, dry matter; $\mathrm{EE}$, ether extract; GE, gross energy; IMSC, inverse multiplicative scatter correction; ME, metabolizable energy; MPLS, modified partial least squared; NDF, neutral detergent fiber; NIRS, near-infrared reflectance spectroscopy; $R_{C v}^{2}$, coefficient of determination for cross-validation; RPD, ratio of the standard error of performance to standard deviation; RSEL, relative standard error of laboratory; $\mathrm{RSQ}_{\mathrm{cal}}$, coefficient of determination for calibration; $\mathrm{RSQ}_{\mathrm{v}}$, coefficient of determination for validation; SD, sample standard deviation; SEC, standard error of calibration; SECV, standard error of cross-validation; SEL, standard error of laboratory; SEP, standard error of prediction; SMSC, standard multiplicative scatter correction; SNV, standard normal variate; SNVD, standard norma variate plus detrend correction; WMSC, weighted multiplicative scatter correction

\section{Acknowledgements}

We thank New Hope Liuhe Limited Liability Company and Beijing TongLiXingKe Agriculture Science \& Technology Co. Ltd. for practical assistant with the collection of corn samples and feed formulation in this study.

\section{Funding}

The design of the study was financially supported by China Special Public Sector Fund in Agriculture (200903006). The collection of data and analysis were funded by National Key Technology Research and Development Program (2011BAD26B0404). The interpretation of data and writing of the manuscript were supported by 111 Project (B16044).

\section{Availability of data and materials}

The authors declare that they do not apply new software and databases. The datasets supporting the conclusions of this article are included within the article.

\section{Authors' contributions}

JTL and QFL designed the study, carried out the experiments and measurements. JTL drafted the manuscript. YQC, XXW and WJY assisted with the animal trail, sample collection, sample pre-treatment and chemical analysis. DFL and LYZ participated in the study's design, coordination, paper writing. All authors read and approved the final manuscript.

\section{Competing interests}

The authors declare that they have no competing interests.

Received: 5 January 2016 Accepted: 24 July 2016

Published online: 04 August 2016

\section{References}

1. de Lange CFM, Birkett SH. Characterization of useful energy content in swine and poultry feed ingredients. Can J Anim Sci. 2005;85:269-80.

2. NRC. Nutrient Requirements of Swine. 11th ed. Washington: National Academies Press; 2012

3. Zhao F, Zhang HF, Hou SS, Zhang ZY. Predicting metabolizable energy of normal corn from its chemical composition in adult pekin ducks. Poult Sci. 2009;87:1603-8.

4. Zijlstra RT, Swift ML, Wang LF, Scott TA, Edney MJ. Short communication: Near infrared reflectance spectroscopy accurately predicts the digestible energy content of barley for pigs. Can J Anim Sci. 2011;91:301-4.

5. Zhou LJ, Zhang LY, Zhang EX, Li JT, Yang WJ, Wang ZY. Rapid determination of swine available energy and amino acids in corn distillers dried grains with solubles by near-infrared reflectance spectroscopy. Anim Feed Sci Technol. 2012;175:198-202.
6. Noblet J, Perez JM. Prediction of digestibility of nutrients and energy values of pig diets from chemical analysis. J Anim Sci. 1993;71:3389-98.

7. Just A, JØrgensen H, Fernandez JA. Prediction of metabolizable energy for pigs on the basis of crude nutrients in the feeds. Livest Prod Sci. 1984;11:105-28.

8. Li QF, Zang JJ, Liu DW, Piao XS, Lai CH, Li DF. Predicting corn digestible and metabolizable energy content from its chemical composition in growing pigs. J Anim Sci Biotech. 2014;5:11-8.

9. Fairbairn SL, Patience JF, Classen HL, Zijlstra RT. The energy content of barley fed to growing pigs: Characterizing the nature of its variability and developing prediction equations for its estimation. J Anim Sci. 1999;77:1502-12.

10. Anderson PV, Kerr BJ, Weber TE, Ziemer CJ, Shurson GC. Determination and prediction of digestible and metabolizable energy from chemical analysis of corn co-products fed to growing pigs. J Anim Sci. 2012;90:1242-54.

11. Kerr BJ, Dozier WA, Shurson GC. Effects of reduced-oil corn distillers dried grains with solubles composition on digestible and metabolizable energy value and prediction in growing pigs. J Anim Sci. 2013;91:3231-43.

12. Ji Y, Zuo L, Wang FL, Li DF, Lai C. Nutritional value of 15 corn gluten meals for growing pigs: Chemical composition, energy content and amino acid digestibility. Arch Anim Nutr. 2012;66:283-302.

13. Fontaine J, Schirmer B, HÖrr J. Near-infrared reflectance spectroscopy (NIRS) enables the fast and accurate prediction of essential amino acid contents. 2 . Results for wheat, barley, corn, triticale, wheat, barn/middlings, rice bran, and sorghum. J Agric Food Chem. 2002;50:3902-11.

14. Jiang HY, Zhu YJ, Wei LM, Dai JR, Song TM, Yan YL, et al. Analysis of protein, starch and oil content of single intact kernels by near infrared reflectance spectroscopy (NIRS) in maize (Zea mays L.). Plant Breed. 2007;126:492-7.

15. Yang $F, H e D, X i e C W$. Analysis and estimate of corn quality by near infrared reflectance (NIR) spectroscopy. In: Photonics and Optoelectronics (SOPO). Wuhan: IEEE; 2011. p. 1-4.

16. McCann MEE, McCracken KJ, Agnew RE. The use of near infrared reflectance spectroscopy (NIRS) for prediction of the nutritive value of barley for growing pigs. Irish J Agric Food Res. 2006;45:187-95.

17. van Barneveld RJ, Nuttall JD, Flinn PC, Osborne BG. Near infrared reflectance measurement of the digestible energy content of cereals for growing pigs. J Near Infrared Spectrosc. 1999;7:1-7.

18. Garnsworthy PC, Wiseman J, Fegeros K. Prediction of chemical, nutritive and agronomic characteristics of wheat by near infrared spectroscopy. J Agric Sci. 2000;135:409-17.

19. AOAC International. Official Methods of Analysis of AOAC International. 18th ed. Gaithersburg: Association of Official Analytical Chemists; 2007.

20. van Soest PJ, Robertson JB, Lewis BA. Methods for dietary fiber, neutral detergent fiber, and non-starch polysaccharides in relation to animal nutrition. J Dairy Sci. 1991;74:3583-97.

21. NRC. Nutrient Requirements of Swine. 10th ed. Washington: National Academies Press; 1998.

22. Adeola. Digestion and balance techniques in pigs. In: Lewis AJ, Southern LL, editors. Swine Nutrition. New York: CRC Press; 2001. p. 903-16.

23. Song GL, Li DF, Piao XS, Chi F, Yang WJ. Apparent ileal digestibility of amino acids and the digestible and metabolizable energy content of high-oil corn varieties and its effects on growth performance of pigs. Arch Anim Nutr. 2003;57:297-306.

24. Kovalenko IG, Rippke GR, Hurburgh CR. Determination of amino acid composition of soybeans (glycine max) by near-infrared spectroscopy. J Agric Food Chem. 2006;54:3485-91.

25. Shenk JS, Westerhaus MO. Analysis of Agriculture and Food Products by Near Infrared Reflectance Spectroscopy. Port Matilda: Infrasoft International; 1993

26. Shenk JS, Westerhaus MO. Population definition, sample selection and calibration procedures for near infrared reflectance spectroscopy. Crop Sci. 1991;31:469-74

27. Shenk JS, Westerhaus MO. Development and Network System Management Manual. Silver Spring: NIR Systems Inc.; 1995.

28. I.S.I. The complete software solution for routine analysis, robust calibrations, and networking. WinISI II Manual. Silver Spring: FOSS NIRSytems/TECATOR, Infrasoft International, LLC; 1998.

29. Williams PC. Implementation of near-infrared technology. In: Williams PC, Norris K, editors. Near-Infrared Technology in the Agricultural and Food Industries, 2nd ed. St. Paul, Minnesota: American Association of Cereal Chemists Inc; 2001. p. 145-69.

30. AACC. Approved Methods of the American Association of Cereal Chemists. 10th ed. St. Paul: AACC; 2000. 
31. Uddin M, Okazaki E, Fukushima H, Turza S, Yumiko Y, Fukuda Y. Nondestructive determination of water and protein in surimi by near-infrared spectroscopy. Food Chem. 2006;96:491-5.

32. Metayer JP, Grosjean F, Castaing J. Study of variability in French cereals. Anim Feed Sci Technol. 1993:43:87-108.

33. Aufrère J, Graviou D, Demarquilli C, Perez JM, Andrieu J. Near infrared reflectance spectroscopy to predict energy value of compound feeds for swine and ruminants. Anim Feed Sci Technol. 1996;62:77-90.

34. Xiccato G, Tricino A, Carazzolo A, Meurens M, Maertens L, Carabaño R. Nutritive evaluation and ingredient prediction of compound feeds for rabbits by near-infrared reflectance spectroscopy. Anim Feed Sci Technol. 1999;77:201-12.

35. Deaville ER, Humphries DJ, Givens DI. Whole crop cereals 2. Prediction of apparent digestibility and energy value from in vitro digestion techniques and near infrared reflectance spectroscopy and chemical composition by near infrared reflectance spectroscopy. Anim Feed Sci Technol. 2009:149:114-24.

36. Quampah A, Huang ZR, Wu JG, Liu HY, Li JR. Estimation of oil content and fatty acid composition in cottonseed kernel powder using near infrared reflectance spectroscopy. J Am Oil Chem Soc. 2012;89:567-75.

37. Norris KH, Barnes RF, Moore JE, Shenk JS. Predicting forage quality by infrared reflectance spectroscopy. J Anim Sci. 1976:43:889-97.

38. Norris KH, Williams PC. Optimization of mathematical treatments of raw near-infrared signal in the measurement of protein in hard red spring wheat. I. Influence of particle size. Cereal Chem. 1984;61:158-61.

39. Losada B, García-Rebollar P, Álvarez C, Cachaldora P, Ibáñez MA, Méndez J, et al. The application of apparent metabolizable energy content of oil seeds and oil seed by-products for poultry from its chemical components, in vitro analysis or near-infrared reflectance spectroscopy. Anim Feed Sci Technol. 2010;160:62-72

\section{Submit your next manuscript to BioMed Central and we will help you at every step:}

- We accept pre-submission inquiries

- Our selector tool helps you to find the most relevant journal

- We provide round the clock customer support

- Convenient online submission

- Thorough peer review

- Inclusion in PubMed and all major indexing services

- Maximum visibility for your research

Submit your manuscript at www.biomedcentral.com/submit

) Biomed Central 